\title{
Long-term warming results in species-specific shifts in seed mass in alpine communities
}

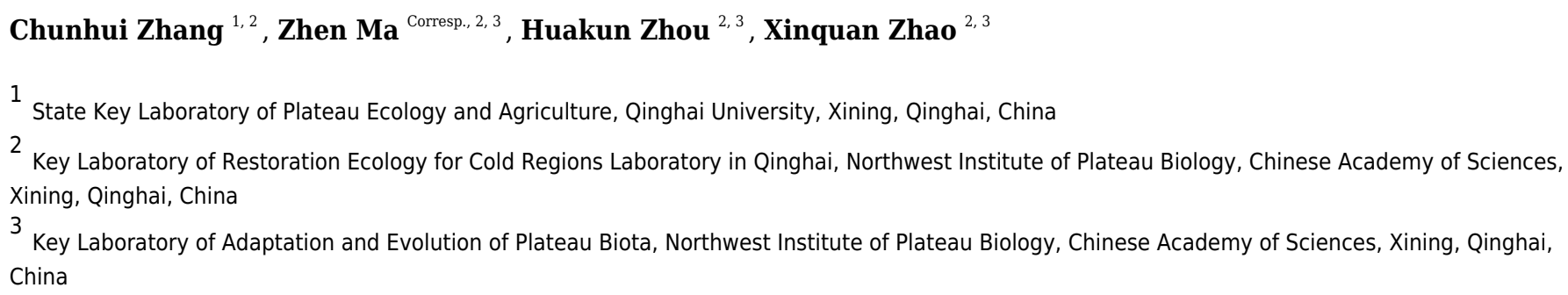

Background. Global warming can cause variation in plant functional traits due to phenotypic plasticity or rapid microevolutionary change. Seed mass represents a fundamental axis of trait variation in plants, from an individual to a community scale. Here, we hypothesize that long-term warming can shift the mean seed mass of species.

Methods. We tested our hypothesis in plots that had been warmed over 18 years in alpine meadow communities with a history of light grazing (LG) and heavy grazing (HG) on the Qinghai-Tibet plateau. In this study, seeds were collected during the growing season of 2015. Results. We found that warming increased the mean seed mass of $4(n=19)$ species in the LG meadow and $6(n=20)$ species in the HG meadow, while decreasing the mean seed mass of 6 species in the LG and HG meadows, respectively. For 7 species, grazing history modified the effect of warming on seed mass. Therefore, we concluded that long-term warming can shift the mean seed mass at the species level. However, the direction of this variation is species-specific. Our study suggests that mean seed mass of alpine plant species appears to decrease in warmer (less stressful) habitats based on lifehistory theory, but it also suggests there may be an underlying trade-off in which mean seed mass may increase due to greater thermal energy inputs into seed development. Furthermore, the physical and biotic environment modulating this trade-off result in complex patterns of variation in mean seed mass of alpine plant species facing global warming. 
1 Long-term warming results in species-specific shifts in seed mass in alpine communities

3 Chunhui Zhang ${ }^{1,2}$, Zhen Ma $^{2,3, *}$, Huakun $Z^{2}{ }^{2,3^{*}}$ \& Xinquan Zhao ${ }^{2,3 *}$

$4{ }^{1}$ State Key Laboratory of Plateau Ecology and Agriculture, Qinghai University, Xining 810016, 5 Qinghai, China;

$6 \quad{ }^{2}$ Key Laboratory of Restoration Ecology for Cold Regions Laboratory in Qinghai, Northwest

7 Institute of Plateau Biology, Chinese Academy of Sciences, Xining 810008, Qinghai, China;

$8 \quad{ }^{3}$ Key Laboratory of Adaptation and Evolution of Plateau Biota, Northwest Institute of Plateau

9 Biology, Chinese Academy of Sciences, Xining, China.

*Corresponding author: Zhen Ma ${ }^{2,3}$ (mazhen@nwipb.cas.cn); Huakun Zhou ${ }^{2,3}$

11 (hkzhou@nwipb.cas.cn); Xinquan Zhao 2,3 (xqzhao@nwipb.cas.cn).

Key Laboratory of Restoration Ecology for Cold Regions Laboratory in Qinghai, Northwest Institute of Plateau Biology, Chinese Academy of Sciences, Xining 810008, Qinghai, China; 
19 ABSTRACT

Background. Global warming can cause variation in plant functional traits due to phenotypic plasticity or rapid microevolutionary change. Seed mass represents a fundamental axis of trait variation in plants, from an individual to a community scale. Here, we hypothesize that long-term warming can shift the mean seed mass of species.

Methods. We tested our hypothesis in plots that had been warmed over 18 years in alpine meadow communities with a history of light grazing (LG) and heavy grazing (HG) on the Qinghai-Tibet plateau. In this study, seeds were collected during the growing season of 2015.

Results. We found that warming increased the mean seed mass of $4(n=19)$ species in the LG meadow and $6(\mathrm{n}=20)$ species in the HG meadow, while decreasing the mean seed mass of 6 species in the LG and HG meadows, respectively. For 7 species, grazing history modified the effect of warming on seed mass. Therefore, we concluded that long-term warming can shift the mean seed mass at the species level. However, the direction of this variation is species-specific. Our study suggests that mean seed mass of alpine plant species appears to decrease in warmer (less stressful) habitats based on life-history theory, but it also suggests there may be an underlying trade-off in which mean seed mass may increase due to greater thermal energy inputs into seed development. Furthermore, the physical and biotic environment modulating this trade-off result in complex patterns of variation in mean seed mass of alpine plant species facing global warming.

\section{INTRODUCTION}


39 2015; Bjorkman et al., 2018). For example, experimental warming resulted in taller plants and

40 larger leaves in Arctic tundra (Hudson et al., 2011; Bjorkman et al., 2018). Such temperature-

41 driven changes in plant traits may reflect either phenotypic variation or rapid microevolutionary

42 change (Thompson, 2013; Merilä \& Hendry, 2014).

43 Seed mass influences temporal and spatial seed dispersal, seedling survival, and the number

44 of seeds that can be produced for a given amount of energy (Fenner \& Thompson, 2005; Moles et

45 al., 2005; Moles et al., 2007). Therefore, it represents a fundamental axis of trait variation in plants,

46 from an individual to a community scale (Westoby et al., 2002; Muller-Landau, 2003; Wright et

47 al., 2007). Theoretically, warming may induce variation in the seed mass of species, although seed

48 mass is generally considered to exhibit relative intraspecific constancy (Harper et al., 1970;

49 Marshall et al., 1986; Michaels et al., 1988; Fenner, 1992; Albert et al., 2012).

50 If air temperature increases, warming may provide greater energy for seed development

51 (Ozkan et al., 2004), and prolonged growing seasons due to warming may lengthen the period of

52 seed development (Sherry et al., 2007), especially in alpine environments where growing seasons

53 are short and air temperatures are low (Körner, 2003; Klein et al., 2004). Previous studies found

54 that shot-term (1-3 year) experimental warming have a positive effect on mean seed mass (i.e.

55 weight per seed) of Dryas octopetala (Wookey et al., 1995), Ranunculus acris (Totland, 1999),

56 Eriophorum vaginatum (Molau \& Shaver, 1997), Saxifraga stellaris (Sandvik, 2001), Ranunculus

57 glacialis (Totland \& Alatalo, 2002), Parnassia palustris (Sandvik \& Eide, 2009), Anemone

58 nemorosa (de Frenne et al., 2011), Cardamine hirsuta (Cao et al., 2016), Koenigia islandica (Cui 
et al., 2017). A recent meta-analysis also found a strong thermal memory for seed mass using thirty species including Arabidopsis, wild and domesticated species from thirty references (FernándezPascual et al., 2019). Therefore, we predict that seeds of species are predicted to become larger in warming environments in this study (termed hypothesis I).

Alternatively, life-history theory proposes a trade-off between seed number and size (i.e., Smith-Fretwell model), i.e., allocation of a given quantity of resource into fewer, larger seeds versus into many, smaller ones (Smith \& Fretwell, 1974; Fenner \& Thompson, 2005). Largerseeded species are considered to be superior competitors and stress-tolerators during establishment (Muller-Landau, 2003; Fenner \& Thompson, 2005). Life-history theory predicts that the minimal maternal investment requirement (i.e., seed mass) may be higher/lower, when the environment becomes harsher/superior (Leishman et al., 2000; Zhang, 2004; Fenner \& Thompson, 2005; Silvertown \& Charlesworth, 2009). For example, low soil fertility significantly increased mean seed mass of Vigna unguiculata from $133 \mathrm{mg}$ to $165 \mathrm{mg}$ (Kahn \& Stoffella, 1985). Equally, the mean seed mass $(0.55 \mathrm{mg})$ of Ranunculus reptans in areas of high density tended to be higher than its mean seed mass $(0.51 \mathrm{mg})$ in areas of low density (van Kleunen et al., 2001). Consequently, we predict that the minimal maternal investment requirement becomes lower when the environment warms (i.e. in a less stressful environment) in alpine environments of the QinghaiTibet Plateau, where plants growth and seeds production are strongly limited by low temperatures and facilitation is the dominant interaction within alpine communities (Körner, 2003; Chu et al., 2008; Wang et al., 2008). In other words, we predict that mean seed mass of species decreases in 
warming environments in this study (termed hypothesis II).

If both mechanisms behind hypothesis I and II exist, their combined effects on seed mass may result in mixed results (i.e. increase, no change or decrease in mean seed mass). Hovenden et al. (2008) found that mean seed mass was not significantly affected by 4-year warming in any of 15 species in temperate grasslands of southeastern Tasmania, Australia. However, there is no empirical study to support hypothesis II.

Grazing, as the main land use and disturbances in alpine communities, has profound influences on physical environment and biotic interactions. Thus, grazing may modify the effect of warming on seed mass. Here, we tested our hypotheses in 18-year warming plots in alpine communities with a light grazing history and heavy grazing history.

\section{MATERIALS \& METHODS}

\section{Study region}

The study was performed at the Haibei Research Station $\left(37^{\circ} 37^{\prime}\right.$ N, $101^{\circ} 12^{\prime}$ E; elevation: 3200 $\mathrm{m})$ in the northeastern Qinghai-Tibet plateau. Mean annual temperature is $-1.7^{\circ} \mathrm{C}$, ranging from $15.2{ }^{\circ} \mathrm{C}$ in January to $9.9^{\circ} \mathrm{C}$ in July (Klein et al., 2004). Mean annual, largely summer, precipitation is $561 \mathrm{~mm}$ (Klein et al., 2004). The growing season generally ranges from May to September (Klein et al., 2004). Soil type is Mollic-Cryic Cambisols (Klein et al., 2004). The grassland types are mainly alpine meadow. The Qinghai-Tibet plateau also has a history of seasonal grazing dating back thousands of years (Zheng et al., 2000). In recent decades, heavy grazing has caused large-scale rangeland degradation (Ma et al., 2014). We identified two sites 
99 (about $1.5 \mathrm{~km}$ apart) with "low" and "high" grazing intensity histories respectively before starting

100 the experiment, namely the low grazing intensity history meadow site (LG meadow) and the high

101 grazing intensity history meadow site (HG meadow). We assigned these qualitative history labels

102 after interviewing local herders and senior researchers about land use patterns and research history

103 at these sites beginning in 1982 (Klein et al., 2004). The "high grazing history site" had both more

104 animals (i.e. sheep) per unite area and animals grazing for a longer duration of time (Klein et al.,

105 2004). Therefore, both the grazing intensity and grazing duration differed among the grazing

106 history sites. The low and high grazing history sites were similar in other features — such as slope,

107 aspect and soil type. Further environmental details about the study region can be found in Klein et 108 al.(2004) and Zhang et al. (2017).

\section{Experimental design and data collection}

In 1997, the two field sites measuring $30 \mathrm{~m} \times 30 \mathrm{~m}$ were located on a flat slope $\left(<1^{\circ}\right)$ and were

fenced off from grazers. Warming was simulated using fiberglass open top chambers (OTCs) in

two field sites from 1997 (see schematic representation of the experiment design in Figure S1).

The OTCs, which were 1.5 and $0.75 \mathrm{~m}$ in diameter at the base, and the top, respectively, and 0.40

m high (see Figure 1), are used by the International Tundra Experiment (Molau \& Mølgaard, 1996)

and are commonly employed to study the effects of climate warming on plant traits, biotic interactions, community structure and functions (Arft et al., 1999; Walker et al., 2006; Liu et al.,

2011; Elmendorf et al., 2012; Sistla et al., 2013; Ylänne et al., 2015; Liu et al., 2016; Rousk et al.,

2016). Each site had eight plots of both warm and control treatments. The OTCs remained on the 
119

120

121

122

123

124

125

126

127

128

129

130

131

132

133

134

135

136

137

138

plots year-round. During the growing season, the OTCs increased the average daily air temperature by $1.0-2.0^{\circ} \mathrm{C}$ (Klein et al., 2005).

During the growing season of 2015, seeds were collected from five ramets for the studied species in warmed and control treatments, respectively. Seeds were air-dried to a constant mass at room temperature (approximately $15^{\circ} \mathrm{C}$ ) before being weighed (Manning et al., 2009; Pivatto et al., 2014; Qi et al., 2014; Zhang et al., 2014a, 2014b). Seed mass was defined as the weight of the embryo, endosperm and seed coat or fruit coat (e.g. Asteraceae seeds of which we cannot separate fruit coat from seed coat). Accessories (e.g. wings, comas, pappus, elaiosomes, fruit flesh) were not included in measures of seed mass (Cornelissen et al., 2003). Total seed mass was weighed and seed number was counted for each of five individuals of each species, and then mean seed mass was computed for each individual of each species. Our seed mass dataset includes 19 species in both warmed and control plots in the LG site and 20 species in both warmed and control plots in the HG site (see supplementary Tables S1, S2 and S3 for their seed mass, seed number and associated characteristics, separately).

See details of the experimental design and microclimate effects of the OTCs in Klein et al. (2004; 2005) and Zhang et al. (2017). each of the six plots for control treatment at two site were divided into three layers of $0-10 \mathrm{~cm}$ and 10-20 cm, and soil from the same depth from a plot was pooled. All soil samples ( 2 depths $\times 6$ plots $\times 2$ sites) were analyzed for total nitrogen, available nitrogen, total phosphorus, available 
139 phosphorus and organic carbon content. These soil characteristics were analyzed using the 140 methods described by Zhang et al. (2019).

\section{Statistical analyses}

142 Prior to analyses, mean seed mass (mg) was ln-transformed to optimize normality of frequency 143 distributions.

A linear mixed-effect model was fitted using the R-package nlme (Pinheiro et al., 2018) with warming treatment and species and their interaction as the fixed effects and plot (nested within site) and site as the random effects to assess the effect of warming on seed mass across all species

147 in both sites. We used Wilcoxon rank sum tests to assess the effect of warming on mean seed mass 148 for each of all species in each site, separately. To examine the main and interactive effects of warming treatment and site on mean seed mass for the species that were found in both LG and HG sites, we conducted a single two-way analysis of variance (ANOVA). Significant interactions meant that the effect of warming on mean seed mass differed between sites. T-tests were used to test if there are significant differences of soil properties of $0-10 \mathrm{~cm}$ and $10-20 \mathrm{~cm}$ in $\mathrm{LG}$ and HG meadow sites. All analyses were conducted in R (http://www.R-project.org).

\section{RESULTS}

We did not find a significant effect of warming on mean seed mass across all species in both sites

156 (Table 1), however, the significant treatment $\times$ species interaction indicates that the effect is 157 species-specific. We found that warming significantly increased the mean seed mass of Euphrasia pectinata, Gentiana aristata, Lomatogonium carinthiacum, and Stipa aliena (4 of 19 species), 
159 160 161

while decreasing the mean seed mass of Deschampsia caespitosa, Draba eriopoda, Elymus nutans, Pedicularis kansuensis, Potentilla nivea, and Taraxacum mongolicum (6 of 19 species) in the LG site (Figure 2A).

Warming significantly increased the mean seed mass of E. pectinata, Gentianopsis barbata, Morina chinensis, P. kansuensis, Ptilagrostis dichotoma, and Saussurea nigrescens (6 of 20 species), while decreasing the mean seed mass of Aster flaccidus, E. nutans, Festuca rubra, Koeleria cristata, Notopterygium forbesii, and S. aliena (6 of 20 species) in the HG site (Figure 2B).

There were significant site $\times$ warming interactions for E. nutans, F. rubra, K. cristata, M. chinensis, P. kansuensis, P. dichotoma, and S. aliena, respectively (Table 2).

\section{DISCUSSION}

In this study, we found that long-term warming can shift the mean seed mass at a species level. However, the direction of this variation is species-specific. We found that warming increased the mean seed mass of 4 of 19 species in the LG meadow and 6 of 20 species in the HG meadow, which support hypothesis I. Moreover, we also found that warming decreased the mean seed mass of 6 of 19 species and 6 of 20 species in the LG and HG meadows, respectively, which support hypothesis II. Thus, the potential for greater energy input and life-history theory in combination determined variation in the mean seed mass of species facing warming in an alpine environment, where plants growth and seeds production are strongly limited by low temperatures (Körner, 2003; Wang et al., 2008). In other words, the two above mechanisms behind hypothesis I and II may act 
179

180

181

182

together and their relative contribution determines changes of mean seed mass under warming. Specifically, under the background of global warming, our study suggests that mean seed mass of alpine plant species appears to decrease in warmer (less stressful) habitats based on life-history theory, but it also suggests there may be an underlying trade-off in which mean seed mass may increase due to the potential for greater energy input. Even though species may inhabit the same community, they do not necessarily face the same physical and biotic environment (Wang et al., 2008). These differences in physical and biotic environments changing relative contribution of the two above mechanisms may result in complex patterns of variation in mean seed mass of alpine plant species facing global warming.

We also reported the interesting result that, for some species, the effect of warming on mean seed mass differed between sites. Particularly, the direction of mean seed mass variation of two species is opposite in LG and HG meadow communities. Mean seed mass of Pedicularis kansuensis decreased due to warming in the LG meadow, but increased in the HG meadow. Mean seed mass of Stipa aliena increased due to warming in the LG meadow, but decreased in the HG meadow. These patterns may be due to different environmental factors (e.g., soil chemical properties) and biotic interactions in these sites. We found that rapidly available nitrogen and rapidly available phosphorus at shallow soil depths $(0-10 \mathrm{~cm})$ were both higher in the LG meadow than the HG meadow, while rapidly available phosphorus at $10-20 \mathrm{~cm}$ was lower in the LG meadow than the HG meadow (Supplementary Table S4). Our previous study found significant changes in species composition between LG and HG meadows (Zhang et al., 2017). For example, 
199

200

201

202

203

204

205

206

207

208

209

210

211

212

213

214

215

216

217

218

compared with the LG meadow, forbs (e.g., Ajania tenuifolia, Aster flaccidus and Saussurea nigrescens) were more abundant in the HG meadow. For those species having a decreased seed mass with warming in the HG meadow, it is possible that high grazing history may have released such species from some form of competition or selective pressure, such that it became favorable for them to produce smaller seeds in greater numbers (hypothesis II). In contrast, for species which had increased seed mass with warming under the HG meadow, it is possible that high grazing history increased stress for those individuals, making it favorable to invest extra energy from warming into larger, more stress-tolerant seeds (hypothesis I). In sum, differences in the physical and biotic environment in two sites may regulate the trade-off between the seedling's chance of survival and mean seed mass, and furthermore induce different variation in mean seed mass of alpine plant species facing environmental warming.

Previous studies have demonstrated correlated evolution among seed/fruit size and other plant trait (e.g. plant height) at a species level (Herrera, 2002; Wright et al., 2007). Other functional traits (e.g. height) may influence the response of mean seed mass to warming. For example, plant height is a major determinant of a species' ability to compete for light (Moles et al., 2009). Previous study has shown that warming tends to increase plant height, probably resulting in more intense competition for light under warming (Hudson et al., 2011). As a result, seed of low plants may become larger at warmer condition to compensate for weak light competitiveness. In addition, closely related species tend to share similar traits (e.g. seed size) or niche preferences (Losos, 2008). Moreover, closely related species may have similar responses of seed size to experimental 
219

220

221

222

224

225

226

227

228

229

230

231

232

233

234

235

236

237

238

warming. Therefore, we conclude that future studies should consider the effects of functional traits and phylogeny on variation in mean seed mass with the background of global warming.

One caveat of our study is that the sites are not replicated within grazing history treatments.

This is the first simulated warming experiment on the Qinghai-Tibet Plateau. In 1990s, funding and harsh environmental conditions limited the scale of the experiment on the Tibetan Plateau. Despite this weakness, this experiment is very valuable for studying the impact of global change on the Qinghai-Tibet Plateau, and many important results (e.g. Klein et al., 2004; Klein et al., 2005;

Wang et al., 2014a; Zhang et al., 2017) were reported based on this experiment. Our research is also of great significance for studying the influence of long-term experimental warming on plant functional traits.

\section{CONCLUSIONS}

We found species-specific changes in mean seed mass but no overall mean seed mass changes in response to long-term experimental warming. The physical and biotic environment may modify the responses of mean seed mass to long-term experimental warming. Previous studies found that intra-specific correlations between seed mass and elevation vary between species (Wang et al., 2014b; Olejniczak et al., 2018). Olejniczak et al. (2018) suggested that we should not expect a single universal pattern in the effects of external factors on plant characteristics. Our findings also conveys this important general ecological message. Furthermore, our study suggests that under the global climate change, multiple mechanisms on variation in plant traits (e.g. seed mass) within different species may coexist, and that should be considered when interpreting community 
239

240

241

242

243

244

245

246

247

248

249

250

251

252

253

254

255

256

257

258

259

260

structure and function from functional traits. In this study, we gave some general explanations for

variation in mean seed mass under long-term experimental warming based on life-history theory

and other hypotheses. However, life history, functional traits, phylogeny, interactions with other

species and soil requirements may influence the response of mean seed mass to warming. In the

future, there is a need to consider the combined effects of these factors on variation in mean seed

mass with the background of global warming.

\section{ACKNOWLEDGEMENTS}

We would like to thank Alison Cassidy at the University of British Columbia for her assistance with English language and grammatical editing of the manuscript.

\section{REFERENCES}

Albert, C. H., de Bello, F., Boulangeat, I., Pellet, G., Lavorel, S., and Thuiller, W. (2012). On the importance of intraspecific variability for the quantification of functional diversity. Oikos 121: 116-126. DOI 10.1111/j.1600-0706.2011.19672.x

Anderegg, W. R. (2015). Spatial and temporal variation in plant hydraulic traits and their relevance for climate change impacts on vegetation. New Phytologist 205: 1008-1014. DOI 10.1111/nph.12907

Arft, A. M., Walker, M. D., Gurevitch, J. E. A., Alatalo, J. M., Bret-Harte, M. S., Dale, M., Diemer, M., Gugerli, F., Henry, G. H. R., Jones, M. H., Hollister, R. D., Jonsdottir, I. S., Laine, K., Levesque, E., Marion, G. M., Molau, U., Molgaard, P., Nordenhall, U., Raszhivin, V., Robinson, C. H., Starr, G., Stenstrom, A., Stenstrom, M., Totland, O., Turner, P. L., Walker, L. J., Webber, P. J., Welker, J. M., and Wookey, P. A. (1999). Responses of tundra plants to 
261

262

263

264

265

266

267

268

269

270

271

272

273

274

275

276

277

278

279

280

281

282

283

284

285

experimental warming: meta-analysis of the international tundra experiment. Ecological Monographs 69: 491-511. DOI 10.2307/2657227

Bjorkman, A. D., Myers-Smith, I. H., Elmendorf, S. C., Normand, S., Rüger, N., Beck, P. S. A., Blach-Overgaard, A., Blok, D., Cornelissen, J. H. C., Forbes, B. C., Georges, D., Goetz, S. J., Guay, K. C., Henry, G. H. R., HilleRisLambers, J., Hollister, R. D., Karger, D. N., Kattge, J., Manning, P., Prevéy, J. S., Rixen, C., Schaepman-Strub, G., Thomas, H. J. D., Vellend, M., Wilmking, M., Wipf, S., Carbognani, M., Hermanutz, L., Lévesque, E., Molau, U., Petraglia, A., Soudzilovskaia, N. A., Spasojevic, M. J., Tomaselli, M., Vowles, T., Alatalo, J. M., Alexander, H. D., Anadon-Rosell, A., Angers-Blondin, S., Beest, M. te, Berner, L., Björk, R. G., Buchwal, A., Buras, A., Christie, K., Cooper, E. J., Dullinger, S., Elberling, B., Eskelinen, A., Frei, E. R., Grau, O., Grogan, P., Hallinger, M., Harper, K. A., Heijmans, M. M. P. D., Hudson, J., Hülber, K., Iturrate-Garcia, M., Iversen, C. M., Jaroszynska, F., Johnstone, J. F., Jørgensen, R. H., Kaarlejärvi, E., Klady, R., Kuleza, S., Kulonen, A., Lamarque, L. J., Lantz, T., Little, C. J., Speed, J. D. M., Michelsen, A., Milbau, A., NabeNielsen, J., Nielsen, S. S., Ninot, J. M., Oberbauer, S. F., Olofsson, J., Onipchenko, V. G., Rumpf, S. B., Semenchuk, P., Shetti, R., Collier, L. S., Street, L. E., Suding, K. N., Tape, K. D., Trant, A., Treier, U. A., Tremblay, J., Tremblay, M., Venn, S., Weijers, S., Zamin, T., Boulanger-Lapointe, N., Gould, W. A., Hik, D. S., Hofgaard, A., Jónsdóttir, I. S., Jorgenson, J., Klein, J., Magnusson, B., Tweedie, C., Wookey, P. A., Bahn, M., Blonder, B., van Bodegom, P. M., Bond-Lamberty, B., Campetella, G., Cerabolini, B. E. L., Chapin, F. S., Cornwell, W. K., Craine, J., Dainese, M., de Vries, F. T., Díaz, S., Enquist, B. J., Green, W., Milla, R., Niinemets, Ü., Onoda, Y., Ordoñez, J. C., Ozinga, W. A., Penuelas, J., Poorter, H., Poschlod, P., Reich, P. B., Sandel, B., Schamp, B., Sheremetev, S., and Weiher, E. (2018). Plant functional trait change across a warming tundra biome. Nature, 562(7725), 57-62. DOI $10.1038 / \mathrm{s} 41586-018-0563-7$

Peer) reviewing PDF | (2018:10:31956:3:0:NEW 25 Jun 2019) 
286

287

288

289

290

291

292

293

294

295

296

297

298

299

300

301

302

303

304

305

306

307

308

309

310

311

312

Cao, Y., Xiao, Y., Huang, H., Xu, J., Hu, W., and Wang, N. (2016). Simulated warming shifts the flowering phenology and sexual reproduction of cardamine hirsuta under different planting densities. Scientific Reports 6: 27835. DOI 10.1038/srep27835

Chu, C., Maestre, F., Xiao, S., Weiner, J., Wang, Y., Duan, Z., and Wang, G. (2008). Balance between facilitation and resource competition determines biomass-density relationships in plant populations. Ecology Letters 11(11): 1189-1197. DOI 10.1111/j.14610248.2008.01228.x

Cornelissen, J., Lavorel, S., Garnier, E., Diaz, S., Buchmann, N., Gurvich, D., Reich, P. B., ter Steege, H., Morgan, H. D., van der Heijden, M. G. A., Pausas, J. G., and Poorter H. (2003). A handbook of protocols for standardised and easy measurement of plant functional traits worldwide. Australian Journal of Botany 51: 335-380. DOI 10.1071/bt02124

Cui, S., Meng, F., Suonan, J., Wang, Q., Li, B., Liu, P., Renzeng, W., Lv, W., Jiang, L., Zhang, L., Li, X., Li, Y., Zhang, Z., Luo, C., Dorji. T., Wang, S. (2017). Responses of phenology and seed production of annual, Koenigia islandica, to warming in a desertified alpine meadow. Agricultural and Forest Meteorology 247: 376-384. DOI 10.1016/j.agrformet.2017.08.034

De Frenne, P., Brunet, J., Shevtsova, A., Kolb, A., Graae, B. J., Chabrerie, O., Ao Cousins, S., Decocq, G., De Schrijver, A., Diekmann, M., Gruwez, R., Heinken, T., Hermy, M., Nilsson, C., Stanton, S., Tack, W., Willaert, J., and Verheyen, K. (2011). Temperature effects on forest herbs assessed by warming and transplant experiments along a latitudinal gradient. Global Change Biology 17(10): 3240-3253. DOI 10.1111/j.1365-2486.2011.02449.x

Elmendorf, S. C., Henry, G. H. R., Hollister, R. D., Björk, R. G., Boulanger-Lapointe, N., Cooper, E. J., Cornelissen, J. H. C., Day, T. A., Dorrepaal, E., Elumeeva, T. G., Gill, M., Gould, W. A., Harte, J., Hik, D. S., Hofgaard, A., Johnson, D. R., Johnstone, J. F., Jónsdóttir, I. S., Jorgenson, J. C., Klanderud, K., Klein, J. A., Koh, S., Kudo, G., Lara, M., Lévesque, E., Magnússon, B., May, J. L., Mercado-Dı'az, J. A., Michelsen, A., Molau, U., Myers-Smith, I. H., Oberbauer, S. F., Onipchenko, V. G., Rixen, C., Schmidt, N. M., Shaver, G. R., Spasojevic, M. J., Pórhallsdóttir, P. E., Tolvanen, A., Troxler, T., Tweedie, C. E., Villareal, 
313

314

315

316

317

318

319

320

321

322

323

324

325

326

327

328

329

330

331

332

333

334

335

336

337

338

339

S., Wahren, C., Walker, X., Webber, P. J., Welker, J. M., and Wipf S. (2012). Plot-scale evidence of tundra vegetation change and links to recent summer warming. Nature Climate Change 2: 453-457. DOI 10.1038/nclimate1465

Fenner, M. (1992). "Environmental influences on seed size and composition," in Horticultural reviews, ed. J. Janick (New York, USA: John Wiley \& Sons), 183-213.

Fenner, M., and Thompson, K. (2005). The ecology of seeds. Cambridge/New York/Port Melbourne/Madrid/The Waterfront: Cambridge University Press.

Fernández-Pascual, E., Efisio, M., and Pritchard, H. W. (2019). Seeds of future past: climate change and the thermal memory of plant reproductive traits. Biological Reviews 94: 439-456. DOI $10.1111 /$ brv.12461

Harper, J. L., Lovell, P., and Moore, K. (1970). The shapes and sizes of seeds. Annual Review of Ecology \& Systematics 2: 327-356. DOI 10.1146/annurev.es.01.110170.001551

Herrera, C. M. (2002). Correlated evolution of fruit and leaf size in bird-dispersed plants: specieslevel variance in fruit traits explained a bit further? Oikos 97: 426-432. DOI 10.1034/j.16000706.2002.970312.x

Hovenden, M. J., Wills, K. E., Vander Schoor, J. K., Chaplin, R.E., Williams, A. L., Nolan, M. J., and Newton P. C. D. (2008). Flowering, seed production and seed mass in a species-rich temperate grassland exposed to FACE and warming. Australian Journal of Botany 55: 780794. DOI $10.1071 / \mathrm{BT} 07107$

Hudson, J., Henry, G., and Cornwell, W. (2011). Taller and larger: shifts in Arctic tundra leaf traits after 16 years of experimental warming. Global Change Biology 17: 1013-1021. DOI 10.1111/j.1365-2486.2010.02294.x

Kahn, B. A., and Stoffella, P. J. (1985). Yield components of cowpeas grown in two environments. Crop Science 25: 179-182. DOI 10.2135/cropsci1985.0011183X002500010043x

Klein, J. A., Harte, J., and Zhao, X. Q. (2004). Experimental warming causes large and rapid species loss, dampened by simulated grazing, on the Tibetan Plateau. Ecology Letters 7: 1170-1179. DOI 10.1111/j.1461-0248.2004.00677.x

Peer) reviewing PDF | (2018:10:31956:3:0:NEW 25 Jun 2019) 
340 Klein, J. A., Harte, J., \& Zhao, X. (2005). Dynamic and complex microclimate responses to 341 warming and grazing manipulations. Global Change Biology 11: 1440-1451. DOI

342

343

350

351

352

353

354

355

356

357

358

359

360

361

362

363

364

365 10.1111/j.1365-2486.2005.00994.x

Körner, C. (2003). Alpine plant life: Functional plant ecology of high mountain ecosystems. Berlin: Springer-Verlag.

Leishman, M. R., Wright, I. J., Moles, A. T., and Westoby, M. (2000). “The evolutionary ecology of seed size," In: Seeds: The ecology of regeneration in plant communities, ed. M. Fenner (Wallingford/New York: CABI), 31-57.

Liu, X., Lyu, S., Zhou, S., and Bradshaw, C. J. A. (2016). Warming and fertilization alter the dilution effect of host diversity on disease severity. Ecology 97: 1680-1689. DOI 10.1890/151784.1

Liu, Y., Reich, P., Li, G., and Sun, S. (2011). Shift phenology and abundance under experimental warming alters trophic relationships and plant reproductive capacity. Ecology 92: 1201-1207. DOI 10.1890/10-2060.1

Losos, J. B. (2008). Phylogenetic niche conservatism, phylogenetic signal and the relationship between phylogenetic relatedness and ecological similarity among species. Ecology Letters 11: 995-1003. DOI 10.1111/j.1461-0248.2008.01229.x

Ma, Z., Ma, M., Baskin, C. C., Li, J., and Du, G. (2014). Responses of alpine meadow seed bank and vegetation to nine consecutive years of soil fertilization. Ecological Engineering 70: 92101. DOI 10.1016/j.ecoleng.2014.04.009

Manning, P., Houston, K., and Evans, T. (2009). Shifts in seed size across experimental nitrogen enrichment and plant density gradients. Basic and Applied Ecology 10: 300-308. DOI 10.1016/j.baae.2008.08.004

Marshall, D. L., Levin, D. A., and Fowler, N. L. (1986). Plasticity of yield components in response to stress in Sesbania macrocarpa and Sesbania vesicaria (Leguminosae). American Naturalist 127: 508-521. DOI 10.1086/284499 
366

367

368

369

370

371

372

373

374

375

376

377

378

379

380

381

382

383

384

385

386

387

388

389

390

391

Merilä, J., and Hendry, A. P. (2014). Climate change, adaptation, and phenotypic plasticity: the problem and the evidence. Evolutionary Applications 7: 1-14. DOI 10.1111/eva.12137

Michaels, H. J., Benner, B., Hartgerink, A., Lee, T., Rice, S., Willson, M. F., and Bertin, R. I. (1988). Seed size variation: magnitude, distribution, and ecological correlates. Ecology \& Evolution 2: 157-166. DOI 10.1007/BF02067274

Molau U., and Mølgaard P. (1996). ITEX Manual. Copenhagen, Denmark: Danish Polar Center.

Molau, U., and Shaver, G. R. (1997). Controls on seed production and seed germinability in Eriophorum vaginatum. Global Change Biology 3(S1): 80-88. DOI 10.1111/j.13652486.1997.gcb130.x

Moles, A. T., Ackerly, D. D., Tweddle, J. C., Dickie, J. B., Smith, R., Leishman, M. R., Mayfield, M. M., Pitman, A. Wood, J. T., and Westoby, M. (2007). Global patterns in seed size. Global Ecology \& Biogeography 16: 109-116. DOI 10.1111/j.1466-8238.2006.00259.x

Moles, A. T., Ackerly, D. D., Webb, C. O., Tweddle, J. C., Dickie, J.B., and Westoby, M. (2005). A brief history of seed size. Science 307: 576-580. DOI 10.1126/science.1104863

Moles, A. T., Warton, D. I., Warman, L., Swenson, N. G., Laffan, S. W., Zanne, A. E., Pitman, A., Hemmings, F. A., \& Leishman, M. R. (2009). Global patterns in plant height. Journal of Ecology 97: 923-932. DOI 10.1111/j.1365-2745.2009.01526.x

Muller-Landau, H. C. (2003). Seeds of understanding of plant diversity. Proceedings of the National Academy of Sciences, USA 100: 1469-1471. DOI 10.1073/pnas.0438004100

Nicotra, A. B., Atkin, O. K., Bonser, S. P., Davidson, A. M., Finnegan, E., Mathesius, U., Poot, P., Purugganan, M. D., Richards, C.L., Valladares, F., and van Kleunen, M. (2010). Plant phenotypic plasticity in a changing climate. Trends in Plant Science 15: 684-692. DOI 10.1016/j.tplants.2010.09.008

Olejniczak, P., Czarnoleski, M., Delimat, A., Majcher, B. M., and Szczepka, K. (2018). Seed size in mountain herbaceous plants changes with elevation in a species-specific manner. PloS one, 13(6), e0199224. DOI 10.1371/journal.pone.0199224 
392

393

394

395

396

397

398

399

400

401

402

403

404

405

406

407

408

409

410

411

412

413

414

415

416

417

418

Ozkan, B., Akcaoz, H., and Fert, C. (2004). Energy input-output analysis in Turkish agriculture. Renewable Energy 29: 39-51. DOI 10.1016/S0960-1481(03)00135-6

Pinheiro, J., Bates, D., DebRoy, S., Sarkar, D., R Core Team (2018). nlme: Linear and Nonlinear Mixed Effects Models. $\mathrm{R}$ package version 3.1-137, https://CRAN.Rproject.org $/$ package $=$ nlme.

Pivatto, M. S., Funes, G., Ferreras, A. E., and Gurvich D. E. 2014. Seed mass, germination and seedling traits for some central Argentinian cacti. Seed Science Research 24: 71-77. DOI https://doi.org/10.1017/S0960258513000366

Qi, W., Guo, S., Chen, X., Cornelissen, J. H. C., Bu, H., and Du, G. (2014). Disentangling ecological, allometric and evolutionary determinants of the relationship between seed mass and elevation: insights from multiple analyses of 1355 angiosperm species on the eastern Tibetan Plateau. Oikos 123: 23-32. DOI 10.1111/j.1600-0706.2013.00448.x

Rousk, K., Michelsen, A., and Rousk, J. (2016). Microbial control of soil organic matter mineralization responses to labile carbon in subarctic climate change treatments. Global Change Biolology 22: 4150-4161. DOI 10.1111/gcb.13296

Sandvik, S. M. (2001). Somatic and demographic costs under different temperature regimes in the late - flowering alpine perennial herb Saxifraga stellaris (Saxifragaceae). Oikos 93(2): 303311. DOI $10.2307 / 3547308$

Sandvik, S. M., and Eide, W. (2009). Costs of reproduction in circumpolar Parnassia palustris 1. in light of global warming. Plant Ecology 205(1): 1-11. DOI 10.1007/s11258-009-9594-3

Sherry, R. A., Zhou, X., Gu, S., Arnone, J. A., Schimel, D. S., Verburg, P.S., Wallace, L. L., and Luo, Y. (2007). Divergence of reproductive phenology under climate warming. Proceedings of the National Academy of Sciences of the United States of America 104: 198-202. DOI 10.1073/pnas.0605642104

Sistla, S. A., Moore, J. C., Simpson, R. T., Gough, L., Shaver, G. R., and Schimel, J. P. (2013). Long-term warming restructures Arctic tundra without changing net soil carbon storage. Nature 497: 615-618. DOI 10.1038/nature12129 
419 Silvertown, J., and Charlesworth, D. (2009). Introduction to plant population biology. New York: $420 \quad$ John Wiley \& Sons.

421 Smith, C. C., and Fretwell, S. D. (1974). The optimal balance between size and number of $422 \quad$ offspring. American Naturalist 108: 499-506. DOI 10.1086/282929

423 Thompson, J. N. (2013). Relentless evolution. Chicago: University of Chicago Press.

424 Totland, Ø. (1999). Effects of temperature on performance and phenotypic selection on plant traits 425 in alpine Ranunculus acris. Oecologia 120(2): 242-251. DOI 10.1007/s004420050854

426 Totland, Ø., and Alatalo, J. M. (2002). Effects of temperature and date of snowmelt on growth, 427 reproduction, and flowering phenology in the arctic/alpine herb, Ranunculus glacialis. Oecologia 133(2): 168-175. DOI 10.1007/s00442-002-1028-z

van Kleunen, M., Fischer, M., and Schmid, B. (2001). Effects of intraspecific competition on size 
446

447

448

449

450

451

452

453

454

455

456

457

458

459

460

461

462

463

464

465

466

467

468

469

470

471

Wang, Y., Wang, J., Lai, L., Jiang, L., Zhuang, P., Zhang, L., Zheng, Y., Baskin, J. M., and Baskin, C. C. (2014b). Geographic variation in seed traits within and among forty - two species of Rhododendron (Ericaceae) on the Tibetan plateau: Relationships with altitude, habitat, plant height, and phylogeny. Ecology and Evolution 4: 1913-1923. DOI 10.1002/ece3.1067

Westoby, M., Falster, D. S., Moles, A. T., Vesk, P. A., and Wright, I. J. (2002). Plant ecological strategies: some leading dimensions of variation between species. Annual Review of Ecology \& Systematics 33: 125-159. DOI 10.1146/annurev.ecolsys.33.010802.150452

Wookey, P. A., Robinson, C. H., Parsons, A. N., Welker, J. M., Press, M. C., Callaghan, T. V., and Lee, J. A. (1995). Environmental constraints on the growth, photosynthesis and reproductive development of Dryas octopetala at a high Arctic polar semi-desert, Svalbard. Oecologia 102: 478-489. DOI 10.1007/BF00341360

Wright, I. J., Ackerly, D. D., Bongers, F., Harms, K. E., Ibarramanriquez, G., Martinez-Ramos, M., Mazer, S. J., Muller-Landau, H. C., Paz, H., Pitman, N. C. A., Poorter, L., Silman, M. R., Vriesendorp, C. F., Webb, C. O., Westoby, M., and Wright, S. J. (2007). Relationships among ecologically important dimensions of plant trait variation in seven Neotropical forests. Annals of Botany 99: 1003-1015. DOI 10.1093/aob/mcl066

Ylänne, H., Stark, S., and Tolvanen, A. (2015). Vegetation shift from deciduous to evergreen dwarf shrubs in response to selective herbivory offsets carbon losses: evidence from 19 years of warming and simulated herbivory in the subarctic tundra. Global Change Biology 21: 36963711. DOI $10.1111 / \mathrm{gcb} .12964$

Zhang, C., Liu, K., Qi, W., Ma, Z. and Du, G. (2014a). Light-dependent associations of germination timing with subsequent life-history traits and maternal habitats for 476 angiosperm species of the eastern Tibetan Plateau grasslands. Seed Science Research 24: 207215. DOI 10.1017/S0960258514000208

Zhang, C., Willis, C. G., Burghardt, L. T., Qi, W., Liu, K., Souzafilho, P. R., Ma, Z., and Du, G. (2014b). The community-level effect of light on germination timing in relation to seed mass: 
472

473

474

475

476

477

478

479

480

481

482

483

484

485

486

487

488

489

490

491

492

493 a source of regeneration niche differentiation. New Phytologist 204: 496-506. DOI 10.1111/nph.12955

Zhang, C., Willis, C. G., Klein, J. A., Ma, Z., Li, J., Zhou, H., and Zhao, X. (2017). Recovery of plant species diversity during long-term experimental warming of a species-rich alpine meadow community on the Qinghai-Tibet plateau. Biological Conservation 213: 218-224. DOI 10.1016/j.biocon.2017.07.019

Zhang, C., Willis, C. G., Ma, Z., Ma, M., Csontos, P., Baskin, C. C. Jerry M. Baskin, J. M., Li, J., Zhou, H., Zhao, X., Yao, B., and Du, G. (2019). Direct and indirect effects of long-term fertilization on the stability of the persistent seed bank. Plant and Soil 438: 239-250. DOI 10.1007/s11104-019-04024-X

Zhang, D. (2004). Plant life-history evolution and reproductive ecology. Beijing, China: Science Press.

Zheng, D., Zhang, Q. and Wu, S. (2000). Mountain geoecology and sustainable development of the Tibetan Plateau. Dordrecht, The Netherlands: Kluwer Academic Publishers.

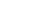


495

496

497

498

499 Supporting information

500 Table S1 Species list and their seed mass.

501 Table S2 Seed number which is used to measure the seed mass for each species.

502 Table S3 Associated characteristics of species.

503 Table S4 Soil properties in LG and HG meadow sites (mean \pm SD). The different letters indicate 504 significant differences of soil properties of 0-10 cm (lowercase letters) and 10-20 cm (uppercase 505 letter) in LG and HG meadow sites $(\mathrm{P}<0.05)$.

506 Figure S1 Schematic representation of the experiment design. 
Figure 1

A photograph of a fiberglass open top chamber (OTC) in the field.

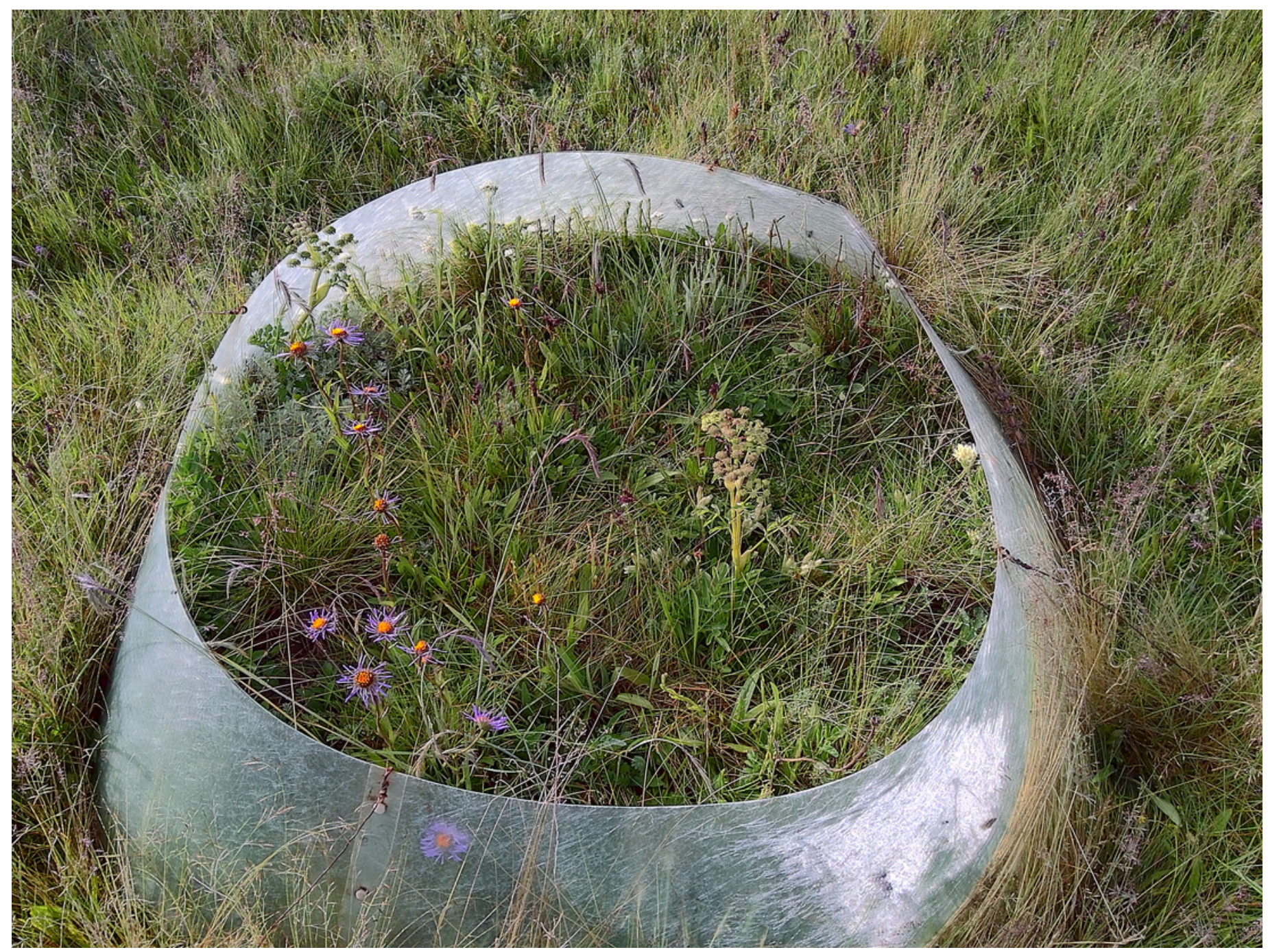


Figure 2

Effects of warming on mean seed mass in the $L G(A)$ and $H G(B)$ meadow sites.

The error bars indicate $\pm \mathrm{SE} ; \mathrm{n}=5$. The asterisks $(*)$ and points (.) indicate the significant differences $(P<0.05)$ and marginally significant differences $(P<0.1)$ between control and warming treatments, respectively. The significance was tested using the Wilcoxon rank sum test.

(A)

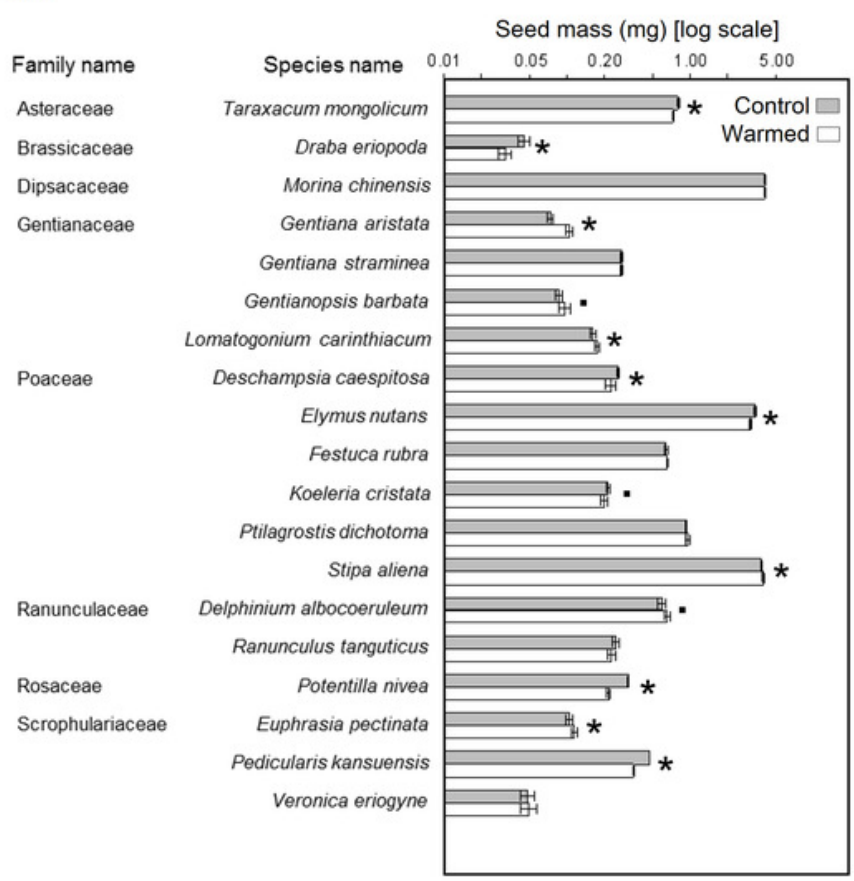

(B)

Family name




\section{Table $\mathbf{1}$ (on next page)}

Results of the linear mixed-effect model (LMM) which was used to assess the effect of warming on seed mass across all species in both LG and HG sites 
1 Table 1 Results of the linear mixed-effect model which was used to assess the effect of warming 2 on seed mass across all species in both LG and HG sites

3

\begin{tabular}{llll}
\hline & $D f$ & $F$-value & $P$ \\
\hline treatment & 1 & 1.14 & 0.2865 \\
species & 25 & 2409.33 & $<0.0001$ \\
treatment $\times$ species & 25 & 7.17 & $<0.0001$ \\
\hline
\end{tabular}

4 


\section{Table 2 (on next page)}

Results of two-way ANOVA including site and warming treatment for each of the species that were found in both LG and HG sites 
1 Table 2 Results of two-way ANOVA including site and warming treatment for each of the species

2 that were found in both LG and HG sites

3

\begin{tabular}{|c|c|c|c|}
\hline Species & Warm & Site & Warm $\times$ Site \\
\hline & $F_{1,16}$ & $F_{1,16}$ & $F_{1,16}$ \\
\hline Deschampsia caespitosa & $14.20 * *$ & $97.46^{* * *}$ & 0.27 \\
\hline Elymus nutans & $101.42 * * *$ & $12.67 * *$ & $9.37 * *$ \\
\hline Euphrasia pectinata & $29.86 * * *$ & $5.83 *$ & 4.02 \\
\hline Festuca rubra & $150.20 * * *$ & $218.50 * * *$ & $207.40 * * *$ \\
\hline Gentiana aristata & $32.32 * * *$ & $19.34 * * *$ & 2.14 \\
\hline Gentiana straminea & 3.36 & $48.09 * * *$ & 2.37 \\
\hline Gentianopsis barbata & $25.57 * * *$ & 3.54 & 3.93 \\
\hline Koeleria cristata & $57.65 * * *$ & $9.04 * *$ & $32.59 * * *$ \\
\hline Lomatogonium carinthiacum & $7.04 *$ & $80.23 * * *$ & 1.12 \\
\hline Morina chinensis & $9.53 * *$ & $92.25 * * *$ & $13.86^{* *}$ \\
\hline Pedicularis kansuensis & $16.72 * * *$ & $404.78 * * *$ & $62.91 * * *$ \\
\hline Ptilagrostis dichotoma & $23.07 * * *$ & $21.18 * * *$ & $9.25 * *$ \\
\hline Stipa aliena & 0.30 & $85.47 * * *$ & $35.15 * * *$ \\
\hline
\end{tabular}

Note: *, $P<0.05 ; * *, P<0.01 ; * * *, P<0.001$; 